\title{
Effects of Parameters for Preparing Carbon Nanotubes on the Capacitances of Manganese-Cobalt-Zinc Oxide/Carbon Nanotube Electrodes
}

\section{Chuen-Chang LIN* and Yu-Sheng HO}

\author{
Department of Chemical \& Materials Engineering, National Yunlin University of Science and Technology, \\ 123 University Road Sec. 3, Douliu, Yunlin 64002, Taiwan
}

* Corresponding author: linchuen@yuntech.edu.tw

\begin{abstract}
A Co (catalyst)-Ti-coated silicon foil on which carbon nanotubes (CNTs) are directly grown by thermal chemical vapor deposition (CVD) with/without $\mathrm{H}_{2}$ and using different temperatures/volume flow rates of $\mathrm{NH}_{3}$ is optionally pretreated with hydrogen-plasma. Thereafter the CNTs are treated with nitrogen-plasma, and a manganese-cobaltzinc oxide film is deposited on the CNTs by radio frequency sputtering. For the CNT electrode, at the 100 th cycle of potential cycling, its specific capacitance at a CNT growing temperature of $750^{\circ} \mathrm{C}$ is higher than those at 700 or $800^{\circ} \mathrm{C}$ and the higher the $\mathrm{NH}_{3}$ flow rate while growing CNTs, the higher the specific capacitance. Furthermore, the specific capacitance of the manganese-cobalt-zinc oxide/CNT electrode for the CNTs grown in $50 \mathrm{~cm}^{3} \mathrm{~min}^{-1} \mathrm{NH}_{3}$ is higher than that without $\mathrm{NH}_{3}$.
\end{abstract}

(C) The Electrochemical Society of Japan, All rights reserved.

Keywords : Ammonia, Thermal CVD, Vertically Aligned CNTs, Electrochemical Capacitors

\section{Introduction}

Electrochemical capacitors are charge-storage devices which possess higher power density/longer cycle life than batteries ${ }^{1,2}$ and higher energy density than conventional capacitors. ${ }^{3}$ Their applications include hybrid power sources, backup power sources, starting power for fuel cells, and burst-power generation in electronic devices. ${ }^{4-8}$ Electrochemical capacitors are classified into two types, electric double layer capacitors (EDLC) and pseudo-capacitors, according to the energy-storage mechanisms. The capacitance of an EDLC arises from the separation of charge at the interface between the electrode and the electrolyte. However, pseudo-capacitance arises from redox reactions of electroactive materials with several oxidation states. ${ }^{1,9-13}$

Carbon nanotubes (CNTs) have high accessible surface areas (nanometer size, hollow structure, and a low ratio of micropores), low resistance, and high stability. These properties make them potentially suitable for fabrication of electrodes in electrochemical capacitors. ${ }^{3,14}$

The most effective catalysts for the production of CNTs by catalytic chemical vapor deposition are known to be transition metals, such as iron $(\mathrm{Fe})$, cobalt $(\mathrm{Co})$, and nickel $(\mathrm{Ni})$. The packing densities of CNTs grown on $\mathrm{Fe}, \mathrm{Co}$, and Ni catalysts are $4 \times 10^{9}$, $4 \times 10^{9}$, and $2 \times 10^{9} \mathrm{~cm}^{-2}$, respectively due to the easy agglomeration of the small sized $\mathrm{Ni}$ particles compared with $\mathrm{Fe}$ or $\mathrm{Co}$ particles. ${ }^{15}$ In order to form catalytic nanoparticles and reduce oxide to metal from the catalytic surface, the catalytic film was pretreated with a RF (radio frequency) hydrogen-plasma. ${ }^{16,17}$ In this study a Co catalyst was pretreated with RF hydrogen-plasma.

After the deposited Ni (catalyst) film was annealed at $850^{\circ} \mathrm{C}$ in hydrogen environment and then pretreated in various gas environments $\left(\mathrm{N}_{2}, \mathrm{H}_{2}, \mathrm{~N}_{2}+\mathrm{H}_{2}\right.$ or $\left.\mathrm{NH}_{3}\right)$, vertically aligned CNTs were grown in bamboo structure by thermal chemical vapor deposition (CVD) of acetylene in an $\mathrm{NH}_{3}$ environment at $850^{\circ} \mathrm{C}$ with the $\mathrm{NH}_{3}$ pre-treatment. ${ }^{18}$ After the deposited Co (catalyst) film was annealed at $800^{\circ} \mathrm{C}$ in hydrogen environment, vertically aligned CNTs were grown by thermal CVD of acetylene (2.4 to 16.7 vol\%) in $\mathrm{NH}_{3}$ environment at $950^{\circ} \mathrm{C}$ without the $\mathrm{NH}_{3}$ pre-treatment. ${ }^{19}$ At atmospheric pressure, Co was used as a catalyst for thermal CVD of vertically aligned CNTs which were controlled by the flow rate of $\mathrm{NH}_{3}$ to $\mathrm{C}_{2} \mathrm{H}_{2}{ }^{20}$

The objectives of this research were to identify effects of Co pretreated with $\mathrm{H}_{2}$ plasma, growing CNT with/without $\mathrm{H}_{2}$, and CNT growing temperatures as well as volume flow rates of $\mathrm{NH}_{3}$ on the CNT morphology and the specific capacitance as well as electrochemical stability of the prepared electrodes. Therefore, we could seek more vertical alignment as well as higher packing density CNTs grown in a simply thermal CVD process at ambient atmospheric pressure (reduce cost and scale up easily) and higher specific capacitance as well as more operational stability of the prepared electrodes.

\section{Experimental}

The silicon foil was used as a substrate due to its lower cost and smoother surface (compared with graphite). The silicon foil $\left(1 \times 1 \times 0.05\right.$ or $\left.1 \times 2 \times 0.05 \mathrm{~cm}^{3}\right)$ was degreased ultrasonically in acetone and pure de-ionized water (Vol. 1:1) for $15 \mathrm{~min}$ and then oven-dried in air $\left(50^{\circ} \mathrm{C}\right)$ to constant weight. Next, the Ti film (barrier layer and lower specific resistance) was deposited on the pretreated and grounded silicon foil substrate by RF magnetron sputtering from a 3-inch disk Ti target (purity: $99.995 \%$, purchased from SCM, INC) in a vacuum chamber with a background pressure of $7 \times 10^{-6}$ Torr. The distance between the target and the substrate was $10 \mathrm{~cm}$. During deposition, the substrate was not intentionally heated. The sputtering time, sputtering pressure, sputtering power, and the volume flow rate of argon were maintained at $90 \mathrm{~min}, 20 \mathrm{mTorr}, 60 \mathrm{~W}$, and $25 \mathrm{~cm}^{3} \mathrm{~min}^{-1}$, respectively.

The Co (catalyst) particles were deposited on the Ti-coated silicon foil by RF magnetron sputtering from a 3-inch disk Co target (purity: $99.9 \%$, purchased from SCM, INC) in a vacuum chamber with a background pressure of $7 \times 10^{-6}$ Torr. The distance between the target and the substrate was $10 \mathrm{~cm}$. The sputtering power, sputtering pressure, sputtering time, and the volume flow rate of argon were maintained at $50 \mathrm{~W}, 5 \mathrm{mTorr}, 10 \mathrm{~min}$, and $25 \mathrm{~cm}^{3} \mathrm{~min}^{-1}$, respectively. Next, the Co-Ti-coated silicon foil was weighed. 
The Co-Ti-coated silicon foil was optionally placed into the reaction chamber $\left(85 \mathrm{~cm}^{3}\right)$ of the apparatus for RF plasma pretreatment (frequency: $13.56 \mathrm{MHz}$ and maximum power: $1000 \mathrm{~W}$ ). Then, the chamber was degassed to $7 \times 10^{-6}$ Torr. Next, $50 \mathrm{~cm}^{3} \mathrm{~min}^{-1}$ of hydrogen gas was introduced to the chamber to maintain its pressure at 5 Torr. The power, time, and temperature for plasma pretreatment were maintained at $50 \mathrm{~W}, 8 \mathrm{~min}$, and $500^{\circ} \mathrm{C}$, respectively. Subsequently, the pretreated Co-Ti-coated silicon foil was weighed.

CNTs were grown on the Co-Ti-coated silicon foil or pretreated Co-Ti-coated silicon foil using thermal CVD with a gas mixture of $\mathrm{C}_{2} \mathrm{H}_{2}\left(50 \mathrm{~cm}^{3} \mathrm{~min}^{-1}\right), \operatorname{Ar}\left(100 \mathrm{~cm}^{3} \mathrm{~min}^{-1}\right), \mathrm{H}_{2}\left(11 \mathrm{~cm}^{3} \mathrm{~min}^{-1}\right)$ or without $\mathrm{H}_{2}$, and different volume flow rates $(40,50$, and $60 \mathrm{~cm}^{3} \mathrm{~min}^{-1}$ ) of $\mathrm{NH}_{3}$ for $20 \mathrm{~min}$ at different temperatures (700, 750 , and $800^{\circ} \mathrm{C}$ ). The CNTs grown on the Co-Ti-coated silicon foil was then weighed.

The CNTs grown on the pretreated Co-Ti-coated silicon foil were placed into the reaction chamber of the apparatus for plasma treatment. Then, the chamber was degassed to $7 \times 10^{-6}$ Torr. Next, $60 \mathrm{~cm}^{3} \mathrm{~min}^{-1}$ of nitrogen gas was introduced to the chamber to maintain its pressure at $1.3 \mathrm{~Pa}$. Subsequently, the CNTs were modified by RF plasma at $150 \mathrm{~W}$ of power for $20 \mathrm{~min}$ of time and then the CNTs grown on the pretreated Co-Ti-coated silicon foil was weighed.

The electrochemical reversibility and stability of manganese oxide can be enhanced by adding an amount of cobalt (10.417.5 at $\%$ ) oxide and the highest specific capacitance was obtained at 16.4 at $\%$ Co $^{21}$ Furthermore, zinc is cheaper than cobalt/manganese and the operational stability of zinc oxide is lower than that of cobalt oxide but higher that of manganese oxide. Therefore, after nitrogenplasma treatment of the CNTs, the manganese-cobalt-zinc oxide film was deposited on the CNTs grown on the pretreated Co-Ti-coated silicon foil by RF magnetron sputtering from a 3-inch disk Mn-Co$\mathrm{Zn}$ oxide $\left(\mathrm{MnO}_{2} / \mathrm{Co}_{3} \mathrm{O}_{4} / \mathrm{ZnO}: \mathrm{Mn} / \mathrm{Co} / \mathrm{Zn}=67.2\right.$ at $\% / 16.4$ at $\%$ / 16.4 at $\%, 99.9 \mathrm{wt} \%$, melting point: about $817^{\circ} \mathrm{C}$, purchased from SCM, INC, USA) target in a vacuum chamber with a background pressure of $7 \times 10^{-6}$ Torr. The distance between the target and the substrate was $8 \mathrm{~cm}$. The sputtering time, sputtering pressure, sputtering power, the substrate temperature, the volume flow rate of oxygen, and the volume flow rate of argon were maintained at $60 \mathrm{~min}, 20 \mathrm{mTorr}, 60 \mathrm{~W}, 500^{\circ} \mathrm{C}, 5 \mathrm{~cm}^{3} \mathrm{~min}^{-1}$ and $25 \mathrm{~cm}^{3} \mathrm{~min}^{-1}$, respectively. Next, the pretreated Co-Ti-coated silicon foil with the manganese-cobalt-zinc oxide thin film was weighed.

Finally, a CNT or manganese-cobalt-zinc oxide/CNT electrode was prepared by the CNTs or manganese-cobalt-zinc oxide/CNTs grown on the Co-Ti-coated silicon foil being transferred to an aluminum current collector sheet (thickness: $0.001 \mathrm{~cm}$ ) coated homogeneously with a slight amount of electrically conductive cement (silver, epoxy resin, and hardener) to prevent the silver paste and aluminum current collector from contacting the electrolyte. The CNT or manganese-cobalt-zinc oxide/CNT electrode was coated with epoxy resin except its surface with grown CNTs or deposited manganese-cobalt-zinc oxide.

Electrochemical measurements for the prepared electrodes were performed using an electrochemical analyzer $(\mathrm{CH}$ Instruments CHI 608B, USA). The three-electrode cell consisted of $\mathrm{Ag} / \mathrm{AgCl}$ as the reference electrode, $\mathrm{Pt}$ as the counter electrode and the prepared CNT or manganese-cobalt-zinc oxide/CNT electrode as the working electrode. The electrolytes were degassed with purified nitrogen gas before voltammetric and nitrogen was passed over the solution during all the measurements. The solution temperature was maintained at $25^{\circ} \mathrm{C}$ by means of circulating water thermostat (HAAKE DC3 and K20, Germany). In our previous study, ${ }^{22}$ it found that the specific capacitance reached a maximum with $\mathrm{H}_{2} \mathrm{SO}_{4}$ by comparing with other electrolytes, therefore, the cyclic voltammetry $(\mathrm{CV})$ in the range $0-1 \mathrm{~V}$ was taken with a $0.1 \mathrm{M}$ aqueous electrolyte $\left(\mathrm{H}_{2} \mathrm{SO}_{4}\right)$ for the prepared CNT electrode. The cyclic voltammetry
(CV) in the range $-0.5-1.5 \mathrm{~V}$ was taken in a $0.5 \mathrm{M}$ aqueous electrolyte $(\mathrm{LiCl}, \mathrm{pH}=6.7)$ for the prepared manganese-cobalt-zinc oxide/CNT electrode since in our previous study, ${ }^{23,24}$ a maximum capacitance of $490 \mathrm{mF} \mathrm{cm}^{-2}$ was obtained in $0.5 \mathrm{M} \mathrm{NaCl}$ and maximum capacitance of $556 \mathrm{mF} \mathrm{cm}^{-2}$ was obtained in $0.5 \mathrm{M} \mathrm{LiCl}$. A CV scan rate of $100 \mathrm{mV} \mathrm{s}^{-1}$ was used in all measurements unless otherwise stated. Capacitance is normalized to $1 \mathrm{~g}$ of CNTs for the prepared CNT electrode or $1 \mathrm{~g}$ of manganese-cobalt-zinc oxide for the prepared manganese-cobalt-zinc oxide/CNT electrode unless otherwise stated.

Micrographs of Co (catalyst) pretreated as well as not pretreated with $\mathrm{H}_{2}$ plasma, the packing density, diameter, length as well as cross-section micrographs of CNTs (Co not pretreated with $\mathrm{H}_{2}$ plasma) grown at different conditions, and manganese-cobalt-zinc oxide deposited on the CNTs grown in $50 \mathrm{~cm}^{3} \mathrm{~min}^{-1} \mathrm{NH}_{3}$ as well as without $\mathrm{NH}_{3}$ were conducted by field emission scanning electron microscope (FE-SEM, JEOL JSM-6700F, Japan). In addition, the nanostructures of CNTs (Co not pretreated with $\mathrm{H}_{2}$ plasma) grown without $\mathrm{H}_{2}$ and in $50 \mathrm{~cm}^{3} \mathrm{~min}^{-1} \mathrm{NH}_{3}$ as well as without $\mathrm{NH}_{3}$ were examined through transmission electron microscope (TEM, JEOL JEM-2010, Japan). Furthermore, the intensity ratios of the C-C stretching mode to the disorder-induced mode of graphite structure for carbon products grown at different conditions were investigated by microscopes Raman spectrometer (inVia, Renishaw, England).

\section{Results and Discussion}

Figure 1 shows the effects of different CNT growing temperatures and different charge-discharge cycles on the specific capacitances of the CNT [grown in $50 \mathrm{~cm}^{3} \mathrm{~min}^{-1} \mathrm{NH}_{3}$ as well as without $\mathrm{H}_{2}$ and not treated with nitrogen-plasma (Co not pretreated with $\mathrm{H}_{2}$ plasma)] electrodes. At the 100th cycle of potential cycling, the specific capacitance increased in the range from 700 to $750^{\circ} \mathrm{C}$ of $\mathrm{CNT}$ growing temperatures and then decreased in the range from 750 to $800^{\circ} \mathrm{C}$. The reason behind this behavior may be that the average surface area density (see S2, S3, and S4 in Table 1) of the CNTs grown at $750^{\circ} \mathrm{C}$ is higher than those at 700 or $800^{\circ} \mathrm{C}$, thus leading to higher capacitance at $750^{\circ} \mathrm{C}$. This picture may be also explained why the CNTs grown at $750^{\circ} \mathrm{C}$ are more vertically aligned than those at 700 or $800^{\circ} \mathrm{C}$ (see Fig. 2), and that less surface contact between the CNTs, and consequently higher surface area is able to contribute to specific capacitance at $750^{\circ} \mathrm{C}$. Furthermore, the specific capacitances for the electrode of the CNTs grown at 750 or $800^{\circ} \mathrm{C}$ increased with the cycle number, although, the specific capacitances for the electrode of the CNTs grown at $700^{\circ} \mathrm{C}$ decreased with the cycle number (see Fig. 1). Since the CNTs

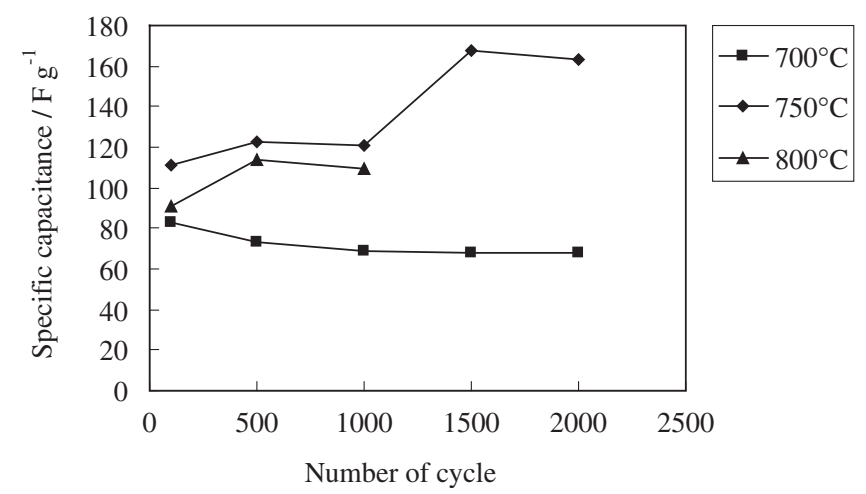

Figure 1. The effects of different CNT growing temperatures and different charge-discharge cycles on the specific capacitances of the CNT [grown in $50 \mathrm{~cm}^{3} \mathrm{~min}^{-1} \mathrm{NH}_{3}$ as well as without $\mathrm{H}_{2}$ and not treated with nitrogen-plasma (Co not pretreated with $\mathrm{H}_{2}$ plasma)] electrodes. 
Table 1. The CNT surface area density $\left(\pi \times\right.$ CNT average diameter $\times$ CNT thickness $\times$ CNT packing density) and $\mathrm{I}_{\mathrm{G}} / \mathrm{I}_{\mathrm{D}}$ for Co (catalyst) not pretreated or pretreated with $\mathrm{H}_{2}$ plasma and the CNTs grown at different conditions as well as not treated with nitrogen-plasma.

\begin{tabular}{|c|c|c|c|c|c|}
\hline $\begin{array}{l}\text { Co not pretreated or pretreated with } \mathrm{H}_{2} \text { plasma } \\
\text { and CNTs grown at different conditions }\end{array}$ & $\begin{array}{l}\text { CNT average } \\
\text { diameter } \\
(\mathrm{nm})\end{array}$ & $\begin{array}{c}\text { CNT } \\
\text { thickness } \\
(\mu \mathrm{m})\end{array}$ & $\begin{array}{c}\text { CNTs packing } \\
\text { density } \\
\left(\mathrm{cm}^{-2}\right)\end{array}$ & $\begin{array}{c}\text { CNT average } \\
\text { surface area density } \\
\left(\mathrm{nm}^{2} \mathrm{~cm}^{-2}\right)\end{array}$ & $\mathrm{I}_{\mathrm{G}} / \mathrm{I}_{\mathrm{D}}$ \\
\hline $\begin{array}{l}\text { S1: Co not pretreated with } \mathrm{H}_{2} \text { plasma and CNTs } \\
\text { grown at } 750^{\circ} \mathrm{C} \text {, without } \mathrm{NH}_{3} \text {, without } \mathrm{H}_{2}\end{array}$ & 34.0 & 5.50 & $1.7 \times 10^{10}$ & $9.98 \times 10^{15}$ & 0.851 \\
\hline $\begin{array}{l}\text { S2: Co not pretreated with } \mathrm{H}_{2} \text { plasma and CNTs } \\
\text { grown at } 700^{\circ} \mathrm{C} \text {, in } 50 \mathrm{~cm}^{3} \mathrm{~min}^{-1} \mathrm{NH}_{3} \text {, without } \mathrm{H}_{2}\end{array}$ & 30.3 & 4.07 & $2.3 \times 10^{10}$ & $8.90 \times 10^{15}$ & 0.821 \\
\hline $\begin{array}{l}\text { S3: Co not pretreated with } \mathrm{H}_{2} \text { plasma and CNTs } \\
\text { grown at } 7500^{\circ} \mathrm{C} \text {, in } 50 \mathrm{~cm}^{3} \mathrm{~min}^{-1} \mathrm{NH}_{3} \text {, without } \mathrm{H}_{2}\end{array}$ & 32.3 & 6.09 & $3.0 \times 10^{10}$ & $1.85 \times 10^{16}$ & 0.919 \\
\hline $\begin{array}{l}\text { S4: Co not pretreated with } \mathrm{H}_{2} \text { plasma and CNTs } \\
\text { grown at } 800^{\circ} \mathrm{C} \text {, in } 50 \mathrm{~cm}^{3} \mathrm{~min}^{-1} \mathrm{NH}_{3} \text {, without } \mathrm{H}_{2}\end{array}$ & 96.3 & 1.44 & $2.7 \times 10^{10}$ & $1.17 \times 10^{16}$ & 0.871 \\
\hline $\begin{array}{l}\text { S5: Co pretreated with } \mathrm{H}_{2} \text { plasma and CNTs } \\
\text { grown at } 7500^{\circ} \mathrm{C} \text {, in } 50 \mathrm{~cm}^{3} \mathrm{~min}^{-1} \mathrm{NH}_{3} \text {, without } \mathrm{H}_{2}\end{array}$ & 30.2 & 6.07 & $4.1 \times 10^{10}$ & $2.35 \times 10^{16}$ & 0.886 \\
\hline $\begin{array}{l}\text { S6: Co pretreated with } \mathrm{H}_{2} \text { plasma and CNTs } \\
\text { grown at } 750^{\circ} \mathrm{C} \text {, in } 50 \mathrm{~cm}^{3} \mathrm{~min}^{-1} \mathrm{NH}_{3} \text {, in } \mathrm{H}_{2}\end{array}$ & 30.12 & 6.11 & $4.3 \times 10^{10}$ & $2.48 \times 10^{16}$ & 0.921 \\
\hline
\end{tabular}

(a)

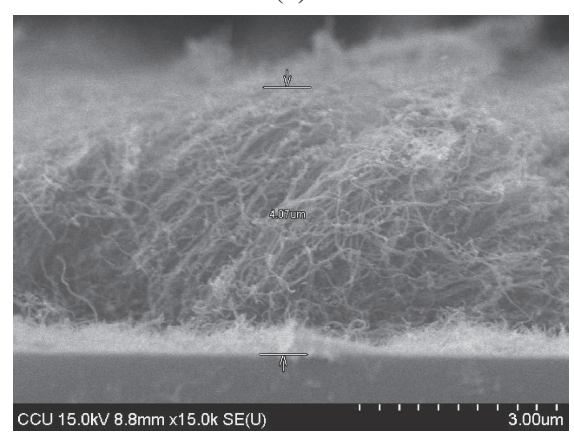

(b)

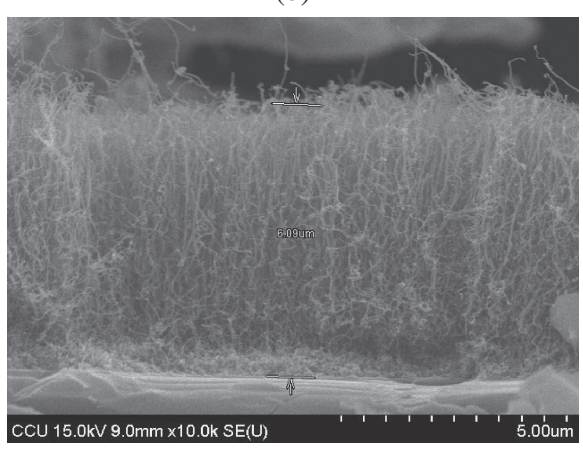

(c)

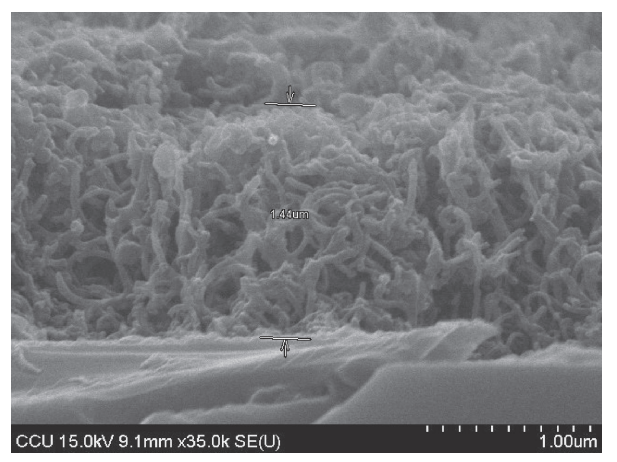

Figure 2. FE-SEM cross-section micrographs of CNTs grown in $50 \mathrm{~cm}^{3} \mathrm{~min}^{-1} \mathrm{NH}_{3}$ as well as without $\mathrm{H}_{2}$ at different temperatures [(a): $700^{\circ} \mathrm{C},(\mathrm{b}): 750^{\circ} \mathrm{C}$, and (c): $\left.800^{\circ} \mathrm{C}\right]$ and not treated with nitrogen-plasma (Co not pretreated with $\mathrm{H}_{2}$ plasma). grown at 750 or $800^{\circ} \mathrm{C}$ have a higher intensity ratio of the C-C stretching mode to the disorder-induced mode of graphite structure for carbon products (see S2, S3, and S4 in Table 1 and Fig. 3), leading to higher crystalline carbon nanotube content. Moreover, the specific capacitances for the electrodes of the CNTs grown at 750 or $800^{\circ} \mathrm{C}$ increased with increasing the cycle number. The reason behind this behavior might be that at a larger number of potential cycles, the percentage of incorporated water from the electrolyte may increase; this causes higher specific capacitance because the combined water (incorporated water and free water from the electrolyte) promotes the movement of protons in the solid phase, ${ }^{25}$ and thus electrolyte ions more easily diffuse into the inner pores of more vertically aligned CNTs (see Fig. 2). Consequently, some potentially electroactive sites on inner pores are able to contribute to specific capacitance with higher levels of combined water.

Figure 4 shows the effects of the CNTs grown in different $\mathrm{NH}_{3}$ flow rates and different charge-discharge cycles on the specific capacitances of the $\mathrm{CNT}$ [grown at $750^{\circ} \mathrm{C}$ without $\mathrm{H}_{2}$ and not treated with nitrogen-plasma (Co not pretreated with $\mathrm{H}_{2}$ plasma)] electrodes. At the 100th cycle of potential cycling, a higher the $\mathrm{NH}_{3}$ flow rate while growing CNTs, leads to higher the specific capacitance. The reason behind this behavior may be explained as follows. The CNTs grown in $50 \mathrm{~cm}^{3} \mathrm{~min}^{-1} \mathrm{NH}_{3}$ led to higher average surface area density (see S1 and S3 in Table 1), thus leading to higher capacitance. The CNTs grown in $50 \mathrm{~cm}^{3} \mathrm{~min}^{-1} \mathrm{NH}_{3}$ are also more vertically aligned than those without $\mathrm{NH}_{3}$ (see Fig. 5), thus leading to higher capacitance for the same reason as above. Furthermore, the specific capacitance for the electrode of the CNTs grown in $50 \mathrm{~cm}^{3} \mathrm{~min}^{-1} \mathrm{NH}_{3}$ increased with the cycle number, but, the specific capacitance for the electrode of the CNTs grown without $\mathrm{NH}_{3}$ decreased with the cycle number (see Fig. 4) because the CNTs grown without $\mathrm{NH}_{3}$ have a larger amount of less organized carbon material (see S1 and S3 in Table 1 and Fig. 3). Moreover, Fig. 6 shows TEM morphologies of CNTs grown at $750^{\circ} \mathrm{C}$ without $\mathrm{H}_{2}$ and in $50 \mathrm{~cm}^{3} \mathrm{~min}^{-1} \mathrm{NH}_{3}$ as well as without $\mathrm{NH}_{3}$ (Co not pretreated with $\mathrm{H}_{2}$ plasma). As shown in the TEM micrograph of Fig. 6(b), the CNTs grown in $50 \mathrm{~cm}^{3} \mathrm{~min}^{-1} \mathrm{NH}_{3}$ have a bamboo-like structure as was often observed in the previous work. ${ }^{26}$

Figure 7 shows the effects of Co (catalyst) not pretreated as well as pretreated with $\mathrm{H}_{2}$ plasma and different charge-discharge cycles on the specific capacitances of the CNT (grown at $750^{\circ} \mathrm{C}$ in $50 \mathrm{~cm}^{3} \mathrm{~min}^{-1} \mathrm{NH}_{3}$ as well as without $\mathrm{H}_{2}$ and not treated with nitrogen-plasma) electrodes. The specific capacitance for Co 
(a)

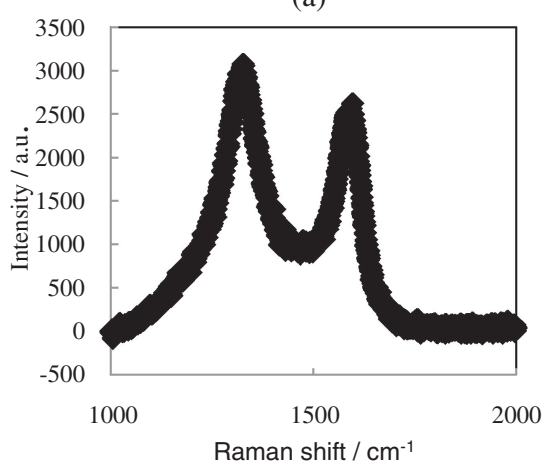

(c)

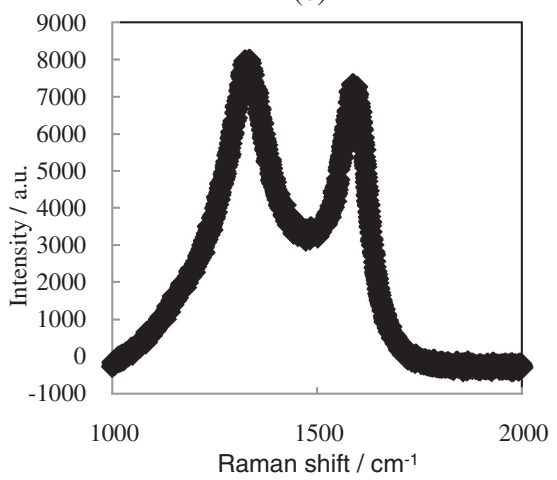

(e)

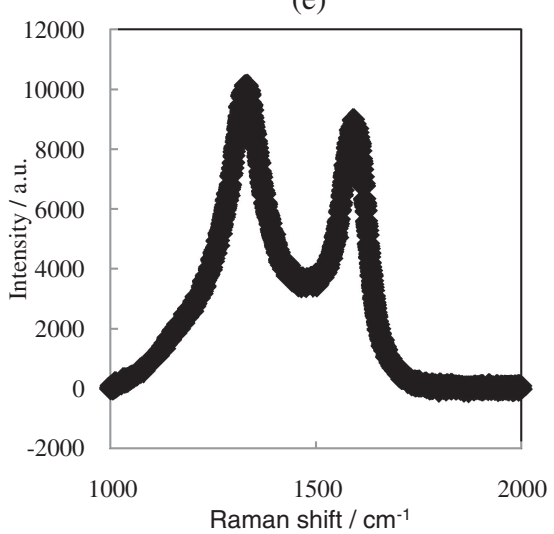

Figure 3. The Raman spectra of CNTs for (a): S1, (b): S2, (c): S3, (d): S4, (e): S5, and (f): S6 in Table 1. (b)

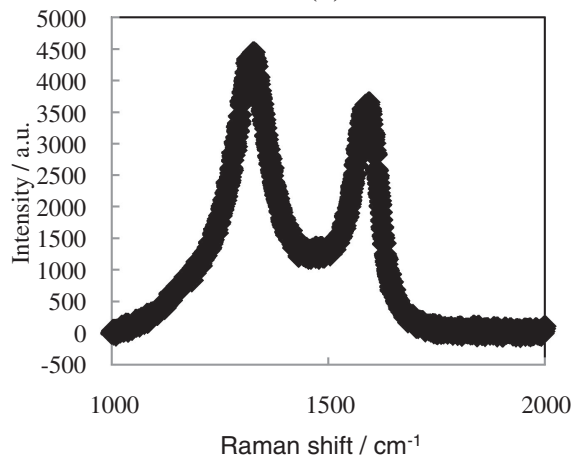

(d)

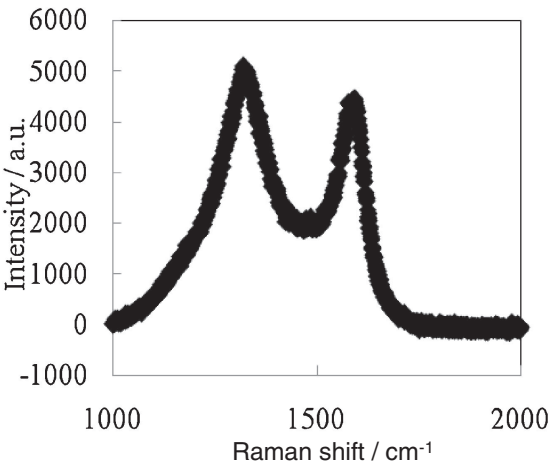

(f)

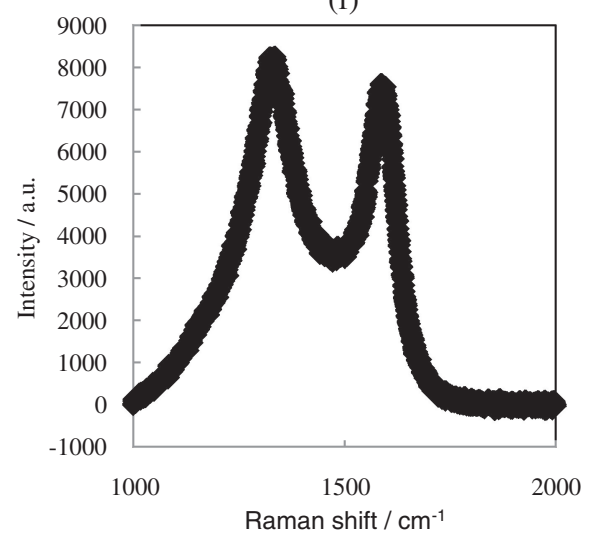

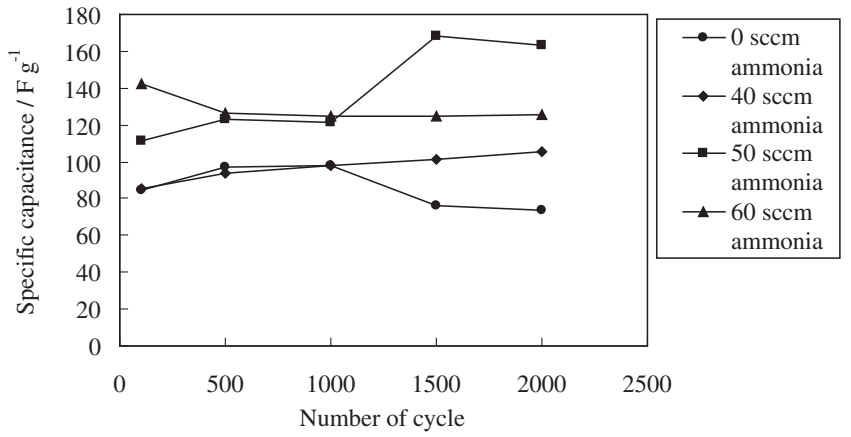

Figure 4. The effects of the CNTs grown in different $\mathrm{NH}_{3}$ flow rates and different charge-discharge cycles on the specific capacitances of the $\mathrm{CNT}$ [grown at $750^{\circ} \mathrm{C}$ without $\mathrm{H}_{2}$ and not treated with nitrogen-plasma (Co not pretreated with $\mathrm{H}_{2}$ plasma)] electrodes. (catalyst) pretreated with $\mathrm{H}_{2}$ plasma is always higher than that for Co (catalyst) not pretreated with $\mathrm{H}_{2}$ plasma. The reason behind this behavior may be explained as follows. Co (catalyst) pretreated with $\mathrm{H}_{2}$ plasma promotes the formation of Co nanoparticles (see Fig. 8) acting as the nucleation seeds for the growth of CNTs as well as reducing Co oxide from the catalytic surface-so keeping the Co (catalyst) active. Thus the average surface area density (see S3 and $\mathrm{S} 5$ in Table 1) for Co (catalyst) pretreated with $\mathrm{H}_{2}$ plasma is higher than that for $\mathrm{Co}$ (catalyst) not pretreated with $\mathrm{H}_{2}$ plasma, thus leading to higher capacitance for Co (catalyst) pretreated with $\mathrm{H}_{2}$ plasma. Furthermore, the curve of the specific capacitance for Co (catalyst) pretreated with $\mathrm{H}_{2}$ plasma is almost the same as that for Co (catalyst) not pretreated with $\mathrm{H}_{2}$ plasma (see Fig. 7) since they have similar Raman spectroscopic characteristics (see S3 and S5 in Table 1 and Fig. 3).

Figure 9 shows the effects of the CNTs grown in $\mathrm{H}_{2}$ as well as without $\mathrm{H}_{2}$ and different charge-discharge cycles on the specific capacitances of the $\mathrm{CNT}$ [grown at $750^{\circ} \mathrm{C}$ in $50 \mathrm{~cm}^{3} \mathrm{~min}^{-1} \mathrm{NH}_{3}$ and not treated with nitrogen-plasma (Co pretreated with $\mathrm{H}_{2}$ plasma)] 
(a)

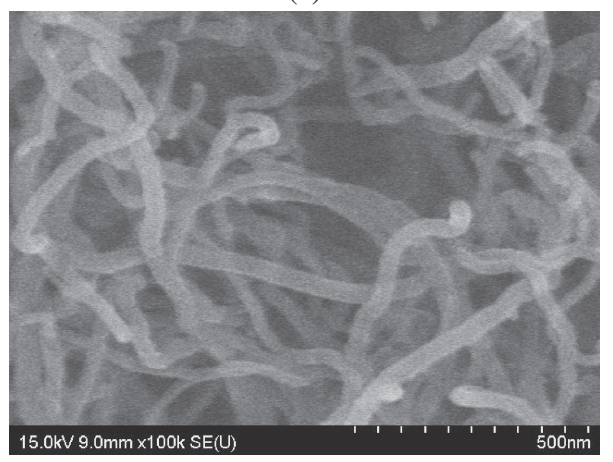

(b)

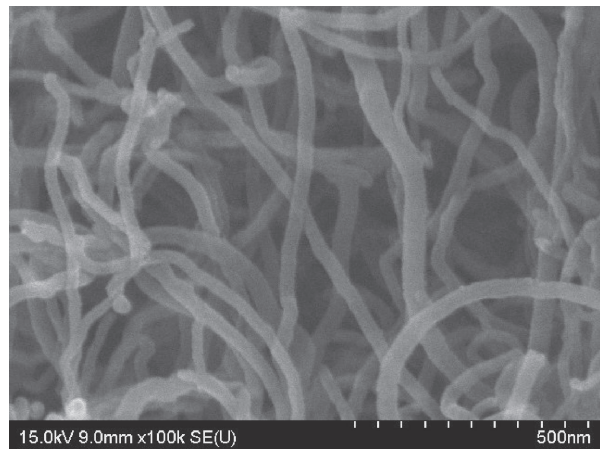

Figure 5. FE-SEM cross-section micrographs of CNTs grown at $750^{\circ} \mathrm{C}$ in $\mathrm{H}_{2}$ as well as (a) without $\mathrm{NH}_{3}$ \& (b) in $50 \mathrm{~cm}^{3} \mathrm{~min}^{-1} \mathrm{NH}_{3}$ and treated with nitrogen-plasma (Co pretreated with $\mathrm{H}_{2}$ plasma).

(a)

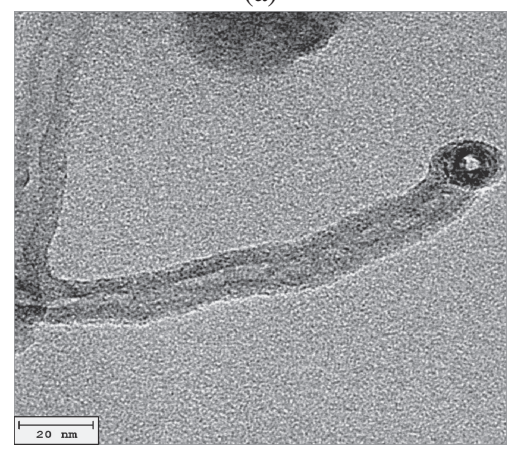

(b)

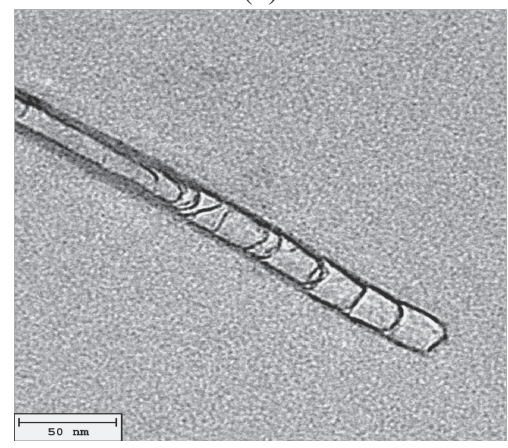

Figure 6. TEM morphologies of CNTs grown at $750^{\circ} \mathrm{C}$ without $\mathrm{H}_{2}$ as well as (a) without $\mathrm{NH}_{3}$ \& (b) in $50 \mathrm{~cm}^{3} \mathrm{~min}^{-1} \mathrm{NH}_{3}$ and not treated with nitrogen-plasma (Co not pretreated with $\mathrm{H}_{2}$ plasma).

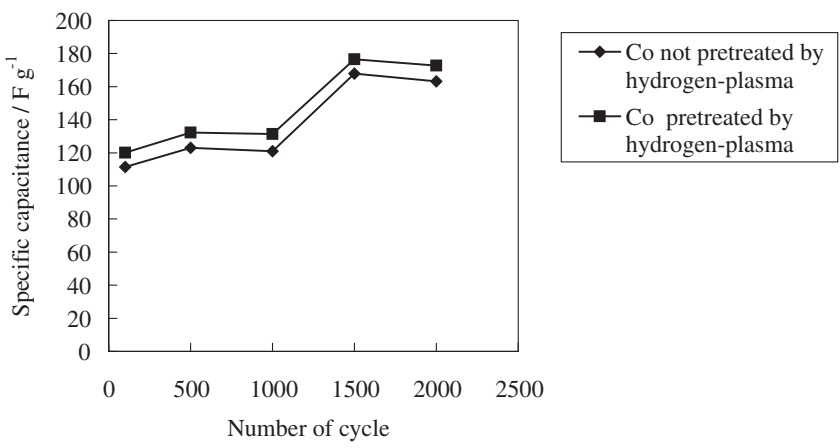

Figure 7. The effects of Co (catalyst) not pretreated as well as pretreated with $\mathrm{H}_{2}$ plasma and different charge-discharge cycles on the specific capacitances of the CNT (grown at $750^{\circ} \mathrm{C}$ in $50 \mathrm{~cm}^{3} \mathrm{~min}^{-1} \mathrm{NH}_{3}$ as well as without $\mathrm{H}_{2}$ and not treated with nitrogen-plasma) electrodes.

(a)

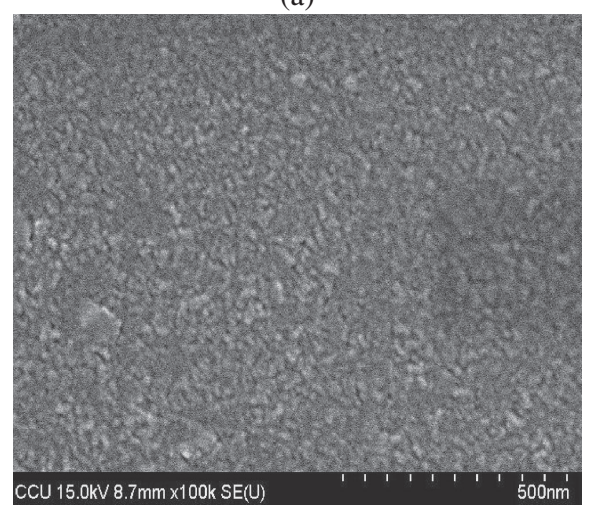

(b)

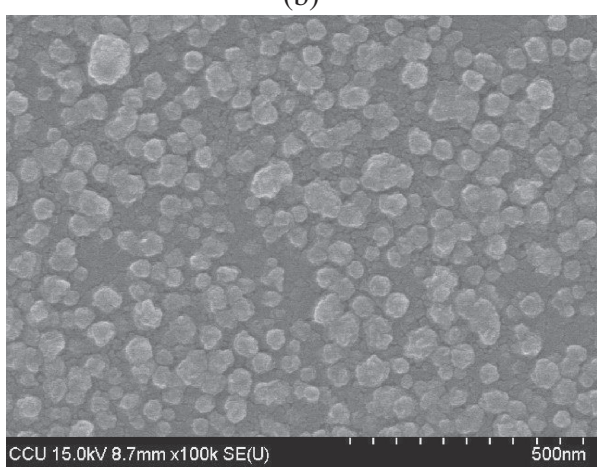

Figure 8. FE-SEM micrographs of (a) Co (catalyst) not pretreated with $\mathrm{H}_{2}$ plasma and (b) Co (catalyst) pretreated with $\mathrm{H}_{2}$ plasma.

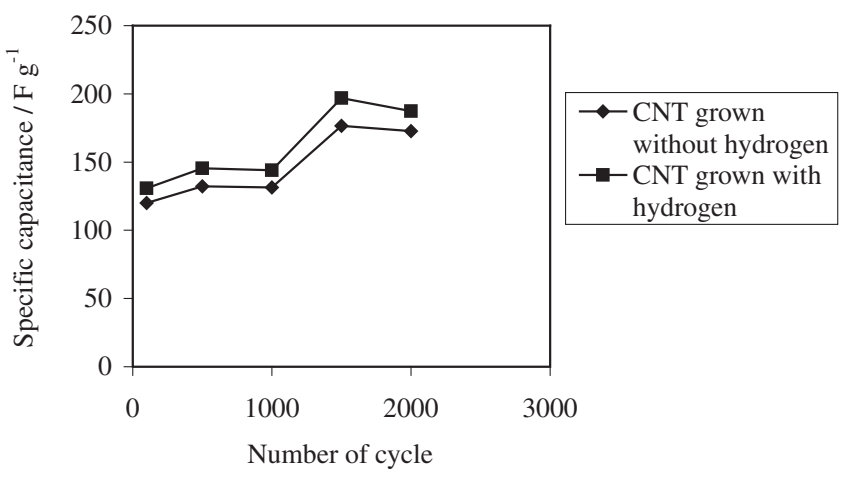

Figure 9. The effects of the CNTs grown in $\mathrm{H}_{2}$ as well as without $\mathrm{H}_{2}$ and different charge-discharge cycles on the specific capacitances of the CNT [grown at $750^{\circ} \mathrm{C}$ in $50 \mathrm{~cm}^{3} \mathrm{~min}^{-1} \mathrm{NH}_{3}$ and not treated with nitrogen-plasma (Co pretreated with $\mathrm{H}_{2}$ plasma)] electrodes. 
(a)

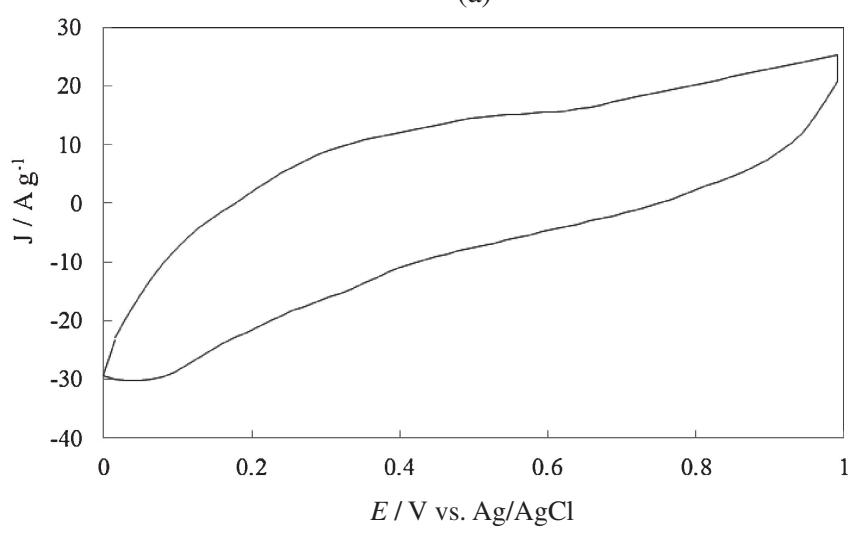

(b)

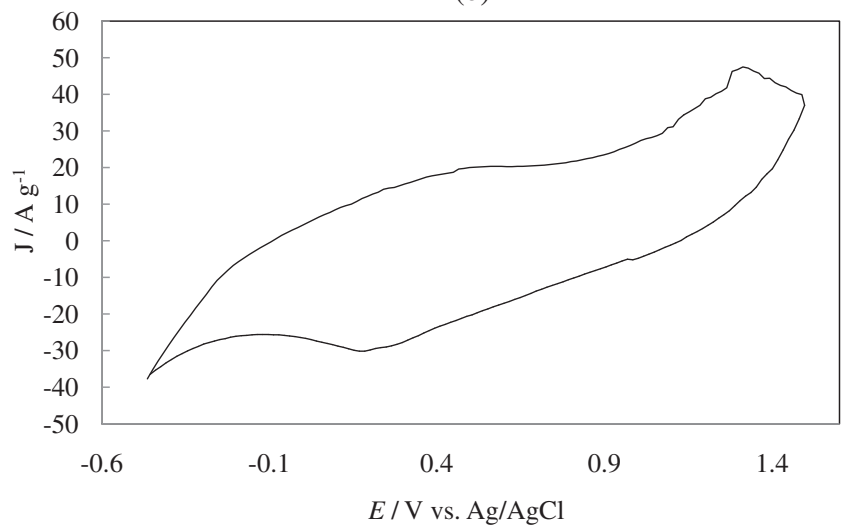

Figure 10. (a) A CV curve at a potential scan rate of $100 \mathrm{mV} \mathrm{s}^{-1}$ in a $0.1 \mathrm{M} \mathrm{H}_{2} \mathrm{SO}_{4}$ solution for the CNT (S6 in Table 1 treated with nitrogen-plasma) electrode and (b) A CV curve at a potential scan rate of $100 \mathrm{mV} \mathrm{s}^{-1}$ in a $0.5 \mathrm{M} \mathrm{LiCl}$ solution for the manganesecobalt-zinc oxide/CNT (S6 in Table 1 treated with nitrogen-plasma) electrode.

electrodes. The specific capacitance of the CNTs grown in $\mathrm{H}_{2}$ is always higher than that without $\mathrm{H}_{2}$. The reason behind this behavior may be that the average surface area density (see S5 and S6 in Table 1) of the CNTs grown in $\mathrm{H}_{2}$ is higher than that without $\mathrm{H}_{2}$, thus leading to higher capacitance. Furthermore, the curve of the specific capacitance of the CNTs grown in $\mathrm{H}_{2}$ is almost the same as that without $\mathrm{H}_{2}$ (see Fig. 9) since they have similar Raman spectroscopic characteristics (see S5 and S6 in Table 1 and Fig. 3).

A CV curve at a potential scan rate of $100 \mathrm{mV} \mathrm{s}^{-1}$ in a $0.1 \mathrm{M}$ $\mathrm{H}_{2} \mathrm{SO}_{4}$ solution for the $\mathrm{CNT}$ [grown at $750^{\circ} \mathrm{C}$ in $50 \mathrm{~cm}^{3} \mathrm{~min}^{-1} \mathrm{NH}_{3}$ as well as in $\mathrm{H}_{2}$ and treated with nitrogen-plasma (Co pretreated with $\mathrm{H}_{2}$ plasma)] electrode is shown in Fig. 10(a), which agrees with the $\mathrm{CV}$ curve reported for other CNT electrode. ${ }^{27,28} \mathrm{~A} \mathrm{CV}$ curve at a potential scan rate of $100 \mathrm{mV} \mathrm{s}^{-1}$ in a $0.5 \mathrm{M} \mathrm{LiCl}$ solution for the manganese-cobalt-zinc oxide/CNT [grown at $750^{\circ} \mathrm{C}$ in $50 \mathrm{~cm}^{3} \mathrm{~min}^{-1} \mathrm{NH}_{3}$ as well as in $\mathrm{H}_{2}$ and treated with nitrogen-plasma (Co pretreated with $\mathrm{H}_{2}$ plasma)] electrode is show in Fig. 10(b), which shows redox peaks due to a Faradic process occurring in manganese-cobalt-zinc oxide.

Figure 11 shows the effects of the CNTs grown in $50 \mathrm{~cm}^{3} \mathrm{~min}^{-1}$ $\mathrm{NH}_{3}$ as well as without $\mathrm{NH}_{3}$ and different charge-discharge cycles on the specific capacitances of the manganese-cobalt-zinc oxide/ CNT [grown at $750^{\circ} \mathrm{C}$ in $\mathrm{H}_{2}$ and treated with nitrogen-plasma (Co pretreated with $\mathrm{H}_{2}$ plasma)] electrodes. The specific capacitance for the CNTs grown in $50 \mathrm{~cm}^{3} \mathrm{~min}^{-1} \mathrm{NH}_{3}$ is always higher than that without $\mathrm{NH}_{3}$. The reason behind this behavior may be explained as follows. The CNTs grown in $50 \mathrm{~cm}^{3} \mathrm{~min}^{-1} \mathrm{NH}_{3}$ are more vertically

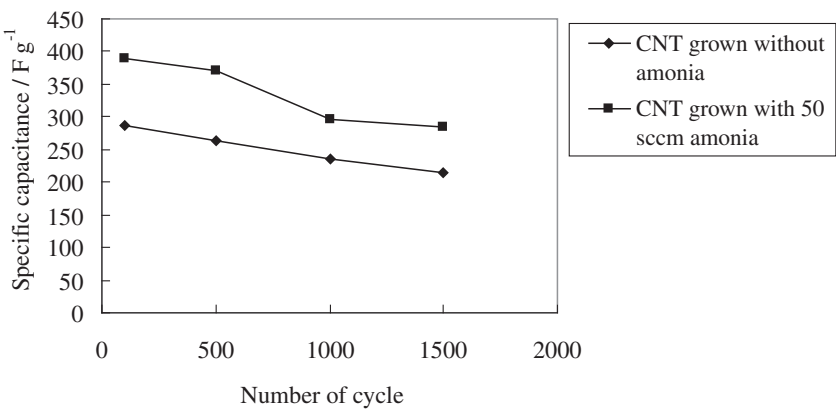

Figure 11. The effects of the CNT grown in $50 \mathrm{~cm}^{3} \mathrm{~min}^{-1} \mathrm{NH}_{3}$ as well as without $\mathrm{NH}_{3}$ and different charge-discharge cycles on the specific capacitances of the manganese-cobalt-zinc oxide/CNT [grown at $750^{\circ} \mathrm{C}$ in $\mathrm{H}_{2}$ and treated with nitrogen-plasma (Co pretreated with $\mathrm{H}_{2}$ plasma)] electrodes.

(a)

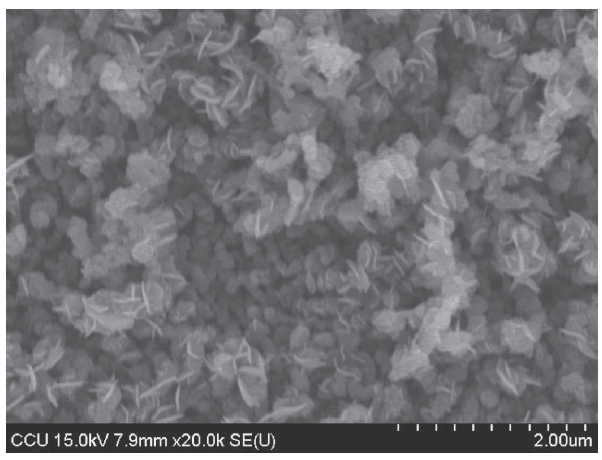

(b)

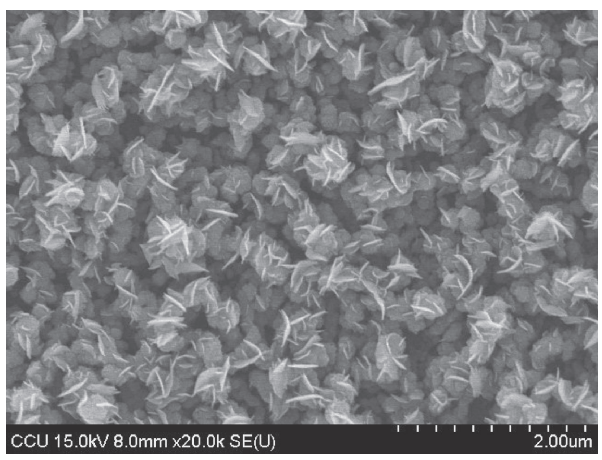

Figure 12. FE-SEM micrographs of the manganese-cobalt-zinc oxide/CNT [grown at $750^{\circ} \mathrm{C}$ in $\mathrm{H}_{2}$, (a) without $\mathrm{NH}_{3}$ as well as (b) in $50 \mathrm{~cm}^{3} \mathrm{~min}^{-1} \mathrm{NH}_{3}$ and treated with nitrogen-plasma (Co pretreated with $\mathrm{H}_{2}$ plasma)] electrode.

aligned than those without $\mathrm{NH}_{3}$ (see Fig. 5), consequently there is less surface contact between the CNTs, thus leading to more $(0.00038 \mathrm{~g})$ of the manganese-cobalt-zinc oxide deposited on the CNTs grown in $50 \mathrm{~cm}^{3} \mathrm{~min}^{-1} \mathrm{NH}_{3}$ than that $(0.00023 \mathrm{~g})$ of the manganese-cobalt-zinc oxide deposited on the CNTs grown without $\mathrm{NH}_{3}$. The average grain diameter of manganese-cobalt-zinc oxide deposited on the CNTs grown in $50 \mathrm{~cm}^{3} \mathrm{~min}^{-1} \mathrm{NH}_{3}$ is also smaller than that of the manganese-cobalt-zinc oxide deposited on the CNTs grown without $\mathrm{NH}_{3}$ (see Fig. 12). Therefore, the greater the amount of manganese-cobalt-zinc oxide as well as the smaller the average grain diameter of manganese-cobalt-zinc oxide, the higher the average surface area density of manganese-cobalt-zinc oxide, and thus the higher the specific capacitance for manganese-cobalt-zinc oxide deposited on the CNTs grown in $50 \mathrm{~cm}^{3} \mathrm{~min}^{-1} \mathrm{NH}_{3}$. 


\section{Conclusion}

The specific capacitance of the CNT electrode for Co pretreated with $\mathrm{H}_{2}$ plasma was higher than that for Co not pretreated with $\mathrm{H}_{2}$ plasma and the specific capacitance of the CNT electrode for the CNTs grown in $\mathrm{H}_{2}$ was higher than that without $\mathrm{H}_{2}$. Furthermore, the specific capacitances for the electrode of the CNTs grown at 750 or $800^{\circ} \mathrm{C}$ increased with the cycle number, whereas, the specific capacitance for the electrode of the CNTs grown at $700^{\circ} \mathrm{C}$ decreased with the cycle number and the CNTs grown at $750^{\circ} \mathrm{C}$ were also more vertically aligned than those at 700 or $800^{\circ} \mathrm{C}$. Moreover, the specific capacitance for the electrode of the CNTs grown in $50 \mathrm{~cm}^{3} \mathrm{~min}^{-1} \mathrm{NH}_{3}$ increased with the cycle number, whereas, the specific capacitance for the electrode of the CNTs grown without $\mathrm{NH}_{3}$ decreased with the cycle number and the CNTs grown in $50 \mathrm{~cm}^{3} \mathrm{~min}^{-1} \mathrm{NH}_{3}$ were also more vertically aligned than those without $\mathrm{NH}_{3}$.

\section{Acknowledgment}

Financial support by the National Science Council of the Republic of China (under grant no. NSC 99-2221-E-224-064- and NSC 100-2221-E-224-036-) is gratefully acknowledged.

\section{References}

1. B. E. Conway, Electrochemical Supercapacitors-Scientific Fundamentals and Technological Applications, Kluwer Academic/Plenum Publishers, New York (1999).

2. R. Kotz and M. Carlen, Electrochim. Acta, 45, 2483 (2000).

3. J. H. Chen, W. Z. Li, D. Z. Wang, S. X. Yang, J. G. Wen, and Z. F. Ren, Carbon,
40, 1193 (2002).

4. Y. S. Chen and C. C. Hu, Electrochem. Solid-State Lett., 6, A210 (2003).

5. Y. U. Jeong and A. Manthiram, J. Electrochem. Soc., 149, A1419 (2002).

6. C. C. Hu and C. C. Wang, J. Electrochem. Soc., 150, A1079 (2003).

7. H. P. Park, O. O. Park, K. H. Shin, C. S. Jin, and J. H. Kim, Electrochem. SolidState Lett., 5, H7 (2002).

8. R. N. Reddy and R. G. Reddy, J. Power Sources, 124, 330 (2003).

9. A. Burke, J. Power Sources, 91, 37 (2000).

10. J. K. Chang and W. T. Tsai, Electrochem. Commun., 6, 666 (2004).

11. M. S. Hong, S. H. Lee, and S. W. Kim, Electrochem. Solid-State Lett., 5, A227 (2002).

12. J. H. Park, J. M. Ko, and O. O. Park, J. Electrochem. Soc., 150, A864 (2003).

13. J. R. Zhang, B. Chen, W. K. Li, J. J. Zhu, and L. P. Jiang, Int. J. Mod. Phys. B, 16, 4479 (2002).

14. C. Li, D. Wang, T. Liang, and X. Wang, Powder Technol., 142, 175 (2004).

15. C. J. Lee, J. Park, and J. A. Yu, Chem. Phys. Lett., 360, 250 (2002).

16. A. Okita, Y. Suda, A. Oda, J. Nakamura, A. Ozki, K. Bhattacharyya, H. Sugawara, and Y. Sakai, Carbon, 45, 1518 (2007)

17. Y. H. Wang, J. Lin, and C. H. A. Huan, Thin Solid Films, 405, 243 (2002).

18. M. Jung, K. Y. Eun, J. K. Lee, Y. J. Baik, K. R. Lee, and J. W. Park, Diamond Relat. Mater., 10, 1235 (2001).

19. M. Jung, K. Y. Eun, Y. J. Baik, K. R. Lee, J. K. Shin, and S. T. Kim, Thin Solid Films, 398-399, 150 (2001).

20. S. Wei, W. P. Kang, J. L. Davidson, and J. H. Huang, Diamond Relat. Mater, 15, 1828 (2006).

21. P. Y. Chuang and C. C. Hu, Mater. Chem. Phys., 92, 138 (2005).

22. C. C. Lin and C. C. Yen, J. Appl. Electrochem., 37, 813 (2007).

23. C. C. Lin and H. W. Chen, J. Appl. Electrochem., 39, 1877 (2009).

24. C. C. Lin and H. W. Chen, Electrochim. Acta, 54, 3073 (2009).

25. S. C. Pang, M. A. Anderson, and W. C. Thomas, J. Electrochem. Soc., 147, 444 (2000).

26. Z. Y. Juang, I. P. Chien, J. F. Lai, T. S. Lai, and C. H. Tsai, Diamond Relat. Mater, 13, 1203 (2004)

27. E. Frackowiak and F. Beguin, Carbon, 39, 937 (2001).

28. Y. Honda, M. Takeshige, H. Shiozaki, T. Kitamura, K. Yoshikawa, S. Chakrabartic, O. Suekane, L. Pan, Y. Nakayama, M. Yamagata, and M. Ishikawa, J. Power Sources, 185, 1580 (2008). 